Este libro forma parte del acervo de la Biblioteca Jurídica Virtual del Instituto de Investigaciones Jurídicas de la UNAM

\title{
BALANCE DE DERECHOS EN DOS REFORMAS PENALES
}

\author{
BALANCE OF RIGHTS IN TWO PENAL REFORMS
}

\begin{abstract}
RESUMEN: El artículo ofrece un comparativo entre los artículos de la Constitución referentes a la reforma penal y las legislaciones penales de Chihuahua y Nuevo León. Asimismo, con el fin de analizar la oferta de derechos en el proceso, se describen las etapas procesales penales en las dos mencionadas entidades federativas. Se concluye que la legislación de Nuevo León dista de apegarse a los preceptos constitucionales, mientras que la de Chihuahua, a pesar de algunos fallos, está más de acuerdo con éstos.
\end{abstract}

Palabras clave: Constitucionalidad, reforma penal, Chihuahua, Nuevo León.

\section{Ana Gabriela FARÍAS CALDERÓN*}

ABSTRACT: This paper offers a comparison between the articles of the Constitution related to the penal reform and the penal legislation of Nuevo León and Chihuahua. With the purpose of analyzing the catalogue of rights during the procedure, the stages of the process in the above mentioned states are described. To conclude, it is stated that Nuevo León's legislation is far from following the constitutional principles, whilst Chihuahua's is mostly aligned with them.
Descriptors: Constitutionality, penal reform, Chihuahua, Nuevo León.

* Politóloga por el Instituto Tecnológico y de Estudios Superiores de Monterrey (ITESM) Campus Monterrey y candidata a maestra en Derecho Constitucional Contemporáneo por el Instituto Tecnológico y de Estudios Superiores de Occidente (ITESO). 


\section{NOTA INTRODUCTORIA}

Toda reforma tiene aspectos no negociables. Es importante tenerlos claros durante la discusión legislativa, así como en la etapa de implementación. Cuando la reforma está estrechamente vinculada con garantías individuales, dichos aspectos se vuelven la médula de la negociación. No se pueden ceder, o la implementación no caminará como se espera.

Este ensayo busca aportar información valiosa para un debate que tendrá que darse en los próximos años en todos los estados de la República: cómo diseñar e implementar un sistema acusatorio oral adecuado a las realidades de cada entidad federativa. Para ello se responderán a preguntas como: ¿Cuáles son las características de dos de los primeros sistemas implementados en el país? ¿Atienden los preceptos constitucionales? ¿Qué clase de modelos son? ¿Cuál ofrece mayores garantías para víctimas e imputados? ¿Cuáles son los errores para poder evitarlos?

Con el fin de determinar si la legislación ofrece un adecuado balance de derechos entre víctima u ofendido e imputado y de qué forma se apegan (o no) a las reglas del juego (tanto constitucionales como teóricas), el presente análisis se dividirá en dos partes. La primera consta de un comparativo entre la Constitución Política de los Estados Unidos Mexicanos (en adelante Constitución) y las legislaciones penales locales de los estados en cuestión.

En la segunda parte se describe el proceso penal en las dos entidades federativas, con el propósito de poner de manifiesto las diferencias en la forma de abordar las etapas del procedimiento penal. En esta sección se utilizan aproximaciones teóricas para determinar si las legislaciones cumplen con el propósito del nuevo modelo penal.

\section{ANÁLISIS CONSTITUCIONAL DE LAS DOS REFORMAS}

A continuación se comparan preceptos del texto constitucional vigente con las legislaciones estatales que competen a este análisis. 


\begin{tabular}{|c|c|c|}
\hline \multicolumn{3}{|c|}{ Principios generales } \\
\hline CPEUM & Legislación Chihuahua & Legislación Nuevo León \\
\hline $\begin{array}{l}\text { Art. 20. El proceso penal será } \\
\text { acusatorio y oral. Se regirá por } \\
\text { los principios de publicidad, } \\
\text { contradicción, concentración, } \\
\text { continuidad e inmediación. }\end{array}$ & $\begin{array}{l}\text { Art. 3. En el proceso penal } \\
\text { se observarán especialmente } \\
\text { los principios de oralidad, } \\
\text { publicidad, igualdad, } \\
\text { inmediación, contradicción, } \\
\text { continuidad y concentración. }\end{array}$ & $\begin{array}{l}\text { Art. } 553 \text { III }(C P P) \text {. Se realizará } \\
\text { sobre la base de la acusación } \\
\text { y se regirá por los principios } \\
\text { de oralidad, inmediación, } \\
\text { concentración, continuidad, } \\
\text { contradicción y publicidad. }\end{array}$ \\
\hline $\begin{array}{l}\text { Art. } 20 \text { A } I . \ldots \text { que los daños } \\
\text { causados por el delito se } \\
\text { reparen. }\end{array}$ & $\begin{array}{l}\text { Art. 23. Se adopta el Principio } \\
\text { de Justicia Restaurativa, } \\
\text { entendido como todo proceso } \\
\text { en el que la víctima u ofendido } \\
\text { y el imputado, o condenado, } \\
\text { participan conjuntamente, de } \\
\text { forma activa, en la resolución } \\
\text { de las cuestiones derivadas } \\
\text { del delito, en busca de un } \\
\text { resultado restaurativo. }\end{array}$ & $\begin{array}{l}\text { Art. 5. A los Tribunales Penales } \\
\text { corresponde la imposición } \\
\text { de las sanciones o medidas } \\
\text { de seguridad, cuando en sus } \\
\text { sentencias declaren la existencia } \\
\text { del delito la responsabilidad } \\
\text { del acusado, y, cuando proceda, } \\
\text { condenar a la reparación del daño } \\
\text { y perjuicio. }\end{array}$ \\
\hline $\begin{array}{l}\text { Art. } 20 \text { A II. Toda audiencia se } \\
\text { desarrollará en presencia del } \\
\text { juez, sin que pueda delegar en } \\
\text { ninguna persona el desahogo y } \\
\text { la valoración de las pruebas. }\end{array}$ & $\begin{array}{l}\text { Art. 309. Constituye un } \\
\text { requisito de validez de } \\
\text { la audiencia la presencia } \\
\text { ininterrumpida del Juez, del } \\
\text { Ministerio Público y del } \\
\text { defensor. Sólo audiencia } \\
\text { intermedia* }\end{array}$ & $\begin{array}{l}\text { Art. 566. La presencia del } \\
\text { Ministerio Público y del } \\
\text { defensor del inculpado durante la } \\
\text { audiencia constituye un requisito } \\
\text { de validez de la misma. }\end{array}$ \\
\hline $\begin{array}{l}\text { Art. } 20 \text { A III. Para los efectos de } \\
\text { la sentencia sólo se considerarán } \\
\text { como prueba aquellas que } \\
\text { hayan sido desahogadas en la } \\
\text { audiencia de juicio. }\end{array}$ & $\begin{array}{l}\text { Art. 35. Los medios de } \\
\text { prueba que se desahoguen } \\
\text { en una audiencia previa a } \\
\text { la de juicio oral, carecen } \\
\text { de valor probatorio para } \\
\text { fundar la sentencia, salvo } \\
\text { las excepciones expresas } \\
\text { previstas por la ley. }\end{array}$ & $\begin{array}{l}\text { Art. 559. Durante la audiencia } \\
\text { el Ministerio Público, el } \\
\text { inculpado y su defensor, con } \\
\text { el objeto de acreditar ciertos } \\
\text { hechos, podrán acordar la } \\
\text { incorporación a la Audiencia de } \\
\text { Juicio Oral, de las declaraciones } \\
\text { de testigos, dictámenes de } \\
\text { peritos, inspecciones o informes } \\
\text { rendidos o practicados en la } \\
\text { Averiguación Previa. }\end{array}$ \\
\hline
\end{tabular}




\begin{tabular}{|c|c|c|}
\hline $\begin{array}{l}\text { Art. } 20 \text { A } I V \text {. El juicio se } \\
\text { celebrará ante un juez que } \\
\text { no haya conocido del caso } \\
\text { previamente. }\end{array}$ & $\begin{array}{l}\text { A lo largo del Código se } \\
\text { establecen tres tipos de juez. }\end{array}$ & $\begin{array}{l}\text { Art. } 560 \text { VII. Dictado el auto } \\
\text { de Apertura del Juicio Oral, } \\
\text { el Juez de Preparación de lo } \\
\text { Penal se inhibirá y remitirá } \\
\text { exclusivamente dicho auto al } \\
\text { Juez de Juicio Oral. }\end{array}$ \\
\hline $\begin{array}{l}\text { Art. } 20 \text { A IV. La presentación de } \\
\text { los argumentos y los elementos } \\
\text { probatorios se desarrollará de } \\
\text { manera pública, contradictoria } \\
\text { y oral. }\end{array}$ & $\begin{array}{l}\text { Art. 327. El debate será } \\
\text { oral, tanto en lo relativo a } \\
\text { los alegatos y argumentos } \\
\text { de todas las partes, como en } \\
\text { todas las declaraciones, la } \\
\text { recepción de las pruebas y, en } \\
\text { general, a toda intervención } \\
\text { de quienes participen en él. }\end{array}$ & $\begin{array}{l}\text { Art. 578. El debate será oral, } \\
\text { tanto en lo relativo a los } \\
\text { alegatos y argumentos de todos } \\
\text { los intervinientes en cuanto } \\
\text { a todas las declaraciones, la } \\
\text { recepción de las pruebas y, en } \\
\text { general a toda intervención de } \\
\text { quienes participen en él. }\end{array}$ \\
\hline $\begin{array}{l}\text { Art. } 20 \mathrm{~V} \text {. La carga de la prueba } \\
\text { para demostrar la culpabilidad } \\
\text { corresponde a la parte } \\
\text { acusadora. }\end{array}$ & $\begin{array}{l}\text { Art. 108. La carga de la prueba } \\
\text { corresponderá al Ministerio } \\
\text { Público. }\end{array}$ & \\
\hline $\begin{array}{l}\text { Art. } 20 \mathrm{~V} \text {. Las partes tendrán } \\
\text { igualdad procesal para sostener } \\
\text { la acusación o la defensa, } \\
\text { respectivamente. }\end{array}$ & $\begin{array}{l}\text { Art. 13. Corresponde a los } \\
\text { jueces preservar el principio } \\
\text { de igualdad procesal y } \\
\text { despejar los obstáculos que } \\
\text { impidan su vigencia o la } \\
\text { debiliten. }\end{array}$ & \\
\hline $\begin{array}{l}\text { Art. } 20 \text { VI. Ningún juzgador } \\
\text { podrá tratar asuntos que estén } \\
\text { sujetos a proceso con cualquiera } \\
\text { de las partes sin que esté } \\
\text { presente la otra. }\end{array}$ & $\begin{array}{l}\text { Art. 13. Los jueces no } \\
\text { podrán mantener, directa o } \\
\text { indirectamente, comunicación } \\
\text { con alguna de las partes o sus } \\
\text { defensores, sobre los asuntos } \\
\text { sometidos a su conocimiento, } \\
\text { salvo con la presencia de } \\
\text { todas ellas. }\end{array}$ & \\
\hline
\end{tabular}


Art. 20 VII. La ley establecerá los beneficios que se podrán otorgar al inculpado cuando acepte su responsabilidad.
Art. $20 \quad I X$. Cualquier prueba obtenida con violación de derechos fundamentales será nula.
Art. 388. El Ministerio Público podrá solicitar la aplicación de una pena inferior hasta en un tercio de la mínima señalada para el delito por el cual acusa. *Aplica en procedimiento abreviado*
Art. 331. Los elementos de prueba no tendrán valor si han sido obtenidos por un medio ilícito, o si no fueron incorporados al proceso conforme a las disposiciones de este Código.
Art. 608. En caso de dictar sentencia condenatoria dentro del Procedimiento Abreviado, el Juez, tratándose de delitos no graves, reducirá un tercio de la pena que le correspondería al inculpado. $\mathrm{Si}$ el delito fuere grave, la reducción será de un cuarto de la pena que correspondería al inculpado.

Art. 559. Las partes podrán expresar lo correspondiente sobre las pruebas ofertadas por su contraparte por considerarlas coincidentes, irrelevantes, innecesarias 0 ilícitas, posteriormente el Juez se pronunciará sobre las pruebas ofrecidas.

\begin{tabular}{|c|c|c|}
\hline \multicolumn{3}{|c|}{ Derechos del imputado } \\
\hline CPEUM & Legislación Chihuahua & Legislación Nuevo León \\
\hline $\begin{array}{l}\text { Art. } 20 \text { B I. A que se } \\
\text { presuma su inocencia } \\
\text { mientras no se declare } \\
\text { su responsabilidad } \\
\text { mediante sentencia } \\
\text { emitida por el juez de } \\
\text { la causa. }\end{array}$ & $\begin{array}{l}\text { Art. 5. El imputado deberá ser } \\
\text { considerado y tratado como } \\
\text { inocente en todas las etapas del } \\
\text { proceso, mientras no se declare } \\
\text { su culpabilidad por sentencia } \\
\text { firme, conforme a las reglas } \\
\text { establecidas en este Código. }\end{array}$ & $\begin{array}{l}\text { Art. } 369 \text { VII. El sobreseimiento } \\
\text { procederá en los casos siguientes: } \\
\text { Cuando existan pruebas que } \\
\text { acrediten fehacientemente la } \\
\text { inocencia del acusado. }\end{array}$ \\
\hline $\begin{array}{l}\text { Art. } 20 \text { B II. Desde } \\
\text { el momento de su } \\
\text { detención se le harán } \\
\text { saber los motivos de la } \\
\text { misma y su derecho a } \\
\text { guardar silencio, el cual } \\
\text { no podrá ser utilizado } \\
\text { en su perjuicio. }\end{array}$ & $\begin{array}{l}\text { Art. } 124 \text { I. El imputado tendrá los } \\
\text { siguientes derechos: Conocer su } \\
\text { derecho a no declarar, y de ser } \\
\text { advertido de que todo lo que en } \\
\text { su caso diga, podrá ser usado en } \\
\text { su contra. }\end{array}$ & $\begin{array}{l}\text { Art. } 1353 A \text {. Al inculpado se } \\
\text { le hará saber que de acuerdo } \\
\text { con la Constitución Política de } \\
\text { los Estados Unidos Mexicanos } \\
\text { goza de los siguientes derechos } \\
\text { durante la averiguación previa: } \\
\text { No declarar. O declarar, si ese es } \\
\text { su deseo, asistido por defensor. }\end{array}$ \\
\hline
\end{tabular}




\begin{tabular}{|c|c|c|}
\hline $\begin{array}{l}\text { Art. } 20 \text { B VII. Será } \\
\text { juzgado antes de } \\
\text { cuatro meses si se } \\
\text { tratare de delitos } \\
\text { cuya pena máxima } \\
\text { no exceda de dos } \\
\text { años de prisión, y } \\
\text { antes de un año si la } \\
\text { pena excediere de } \\
\text { ese tiempo, salvo que } \\
\text { solicite mayor plazo } \\
\text { para su defensa. }\end{array}$ & $\begin{array}{l}\text { Art. 65. El proceso penal por } \\
\text { delito cuya pena máxima de } \\
\text { prisión no exceda de dos años, } \\
\text { deberá tramitarse en el plazo } \\
\text { de cuatro meses, y antes de un } \\
\text { año si la pena excediere de este } \\
\text { tiempo. }\end{array}$ & $\begin{array}{l}\text { Art. } 204 X \text {. El Juez está obligado } \\
\text { a hacer saber al inculpado, que } \\
\text { tiene derecho a ser juzgado } \\
\text { antes de cuatro meses si se trata } \\
\text { de delito cuya pena máxima no } \\
\text { exceda de dos años de prisión } \\
\text { y antes de un año si la pena } \\
\text { excediere de ese tiempo, salvo } \\
\text { que solicite mayor plazo para su } \\
\text { defensa. }\end{array}$ \\
\hline $\begin{array}{l}\text { Art. } 20 \text { B IX. La prisión } \\
\text { preventiva no podrá } \\
\text { exceder del tiempo } \\
\text { que como máximo } \\
\text { de pena fije la ley al } \\
\text { delito que motivare el } \\
\text { proceso y en ningún } \\
\text { caso será superior a } \\
\text { dos años, salvo que } \\
\text { su prolongación se } \\
\text { deba al ejercicio del } \\
\text { derecho de defensa } \\
\text { del imputado. Si } \\
\text { cumplido este término } \\
\text { no se ha pronunciado } \\
\text { sentencia, el imputado } \\
\text { será puesto en libertad } \\
\text { de inmediato mientras } \\
\text { se sigue el proceso. }\end{array}$ & $\begin{array}{l}\text { Art.158. Tratándose de medidas } \\
\text { cautelares que impliquen } \\
\text { privación de la libertad, en } \\
\text { ningún caso podrá sobrepasar } \\
\text { la pena mínima prevista para el } \\
\text { delito de que se trate, ni exceder } \\
\text { el plazo fijado en el artículo 182, } \\
\text { fracción II. La prisión preventiva } \\
\text { finalizará cuando su duración } \\
\text { exceda de doce meses. }\end{array}$ & $\begin{array}{l}\text { Art. } 224 \text { XIV. Se impondrán las } \\
\text { sanciones previstas en este } \\
\text { Capítulo alos servidores públicos, } \\
\text { empleados o auxiliares de la } \\
\text { Administración y Procuración } \\
\text { de Justicia y de los Tribunales } \\
\text { Administrativos, que cometan } \\
\text { alguno de los siguientes delitos: } \\
\text { prolongar la prisión preventiva } \\
\text { por más tiempo del que como } \\
\text { máximo fije la ley al delito que } \\
\text { motive el proceso. }\end{array}$ \\
\hline
\end{tabular}

\begin{tabular}{|l|l|l|}
\hline \multicolumn{3}{|c|}{ Derechos de la víctima } \\
\hline \multicolumn{1}{|c|}{ CPEUM } & \multicolumn{1}{|c|}{ Legislación Chihuahua } & \multicolumn{1}{|c|}{ Legislación Nuevo León } \\
\hline $\begin{array}{l}\text { Art. 20 C II. Coadyuvar con } \\
\text { el Ministerio Público. }\end{array}$ & $\begin{array}{l}\text { Art. 122. La víctima u ofendido } \\
\text { podrá constituirse como } \\
\text { acusador coadyuvante, y en tal } \\
\text { caso se le tendrá como parte } \\
\text { para todos los efectos legales. }\end{array}$ & $\begin{array}{l}\text { Art. 8 II. En todo procedimiento } \\
\text { penal, la víctima o el ofendido } \\
\text { derecho a coadyuvar con el } \\
\text { Ministerio Público. }\end{array}$ \\
\hline
\end{tabular}




\begin{tabular}{|c|c|c|}
\hline $\begin{array}{l}\text { Art. } 20 \text { C IV. Que se le repare } \\
\text { el daño. }\end{array}$ & $\begin{array}{l}\text { Art. } 121 \text { XII. La víctima u } \\
\text { ofendido tendrá los siguientes } \\
\text { derechos: solicitar de manera } \\
\text { directa, la reparación del } \\
\text { daño en los casos que sea } \\
\text { procedente. }\end{array}$ & $\begin{array}{l}\text { Art. 7. En el procedimiento } \\
\text { penal ante el Juez, corresponde } \\
\text { al Ministerio Público exigir } \\
\text { la reparación del daño y } \\
\text { perjuicio, en los términos } \\
\text { previstos por la Ley. }\end{array}$ \\
\hline $\begin{array}{l}\text { Art. } 20 \text { C VII. Impugnar } \\
\text { ante autoridad judicial las } \\
\text { omisiones del Ministerio } \\
\text { Público en la investigación } \\
\text { de los delitos, así como } \\
\text { las resoluciones de } \\
\text { reserva, no ejercicio, } \\
\text { desistimiento de la acción } \\
\text { penal o suspensión del } \\
\text { procedimiento cuando } \\
\text { no esté satisfecha la } \\
\text { reparación del daño. }\end{array}$ & $\begin{array}{l}\text { Art. } 121 \text { IX y X. La víctima u } \\
\text { ofendido tendrá los siguientes } \\
\text { derechos: Solicitar la } \\
\text { reapertura de la investigación } \\
\text { cuando se haya decretado el } \\
\text { archivo temporal; Apelar del } \\
\text { sobreseimiento. }\end{array}$ & $\begin{array}{l}\text { Art. } 4 \text { IX. La resolución de } \\
\text { inejercicio de la acción penal } \\
\text { dictada por el Agente del MP } \\
\text { también podrá ser impugnada } \\
\text { por vía jurisdiccional en los } \\
\text { términos que establezca la } \\
\text { ley de la materia. Art. } 385 \\
\text { Son apelables en el afecto } \\
\text { devolutivo: Los autos en que } \\
\text { se decrete el sobreseimiento, } \\
\text { los autos en que se niegue o } \\
\text { se conceda la suspensión del } \\
\text { procedimiento judicial. }\end{array}$ \\
\hline
\end{tabular}

Legislación utilizada: Código de Procedimientos Penales de Chihuahua; Código de Procedimientos Penales de Nuevo León; Código Penal.

\section{BALANCE DE DERECHOS}

Como se puede apreciar en la tabla anterior, en el rubro de principios generales, la legislación de Chihuahua está mayoritariamente a tono con los preceptos establecidos en la Constitución. Dicho estado de la República comenzó a implementar el sistema acusatorio antes de que se realizaran los cambios a nivel federal. Tomando esto en cuenta, que cumpla con la mayor parte de los requisitos habla bien de su legislación, pero también delinea áreas de oportunidad importantes.

Si bien se puede inferir que adelantarse a lo que establecería la Constitución es sinónimo de que se guía por principios sólidos, también es cierto que es necesario realizar los cambios pertinentes. En los próximos párrafos se mencionan cuáles.

La presencia del juez como requisito de validez de una audiencia tiene como propósito el que la justicia sea impartida por quien está más capacitado (más allá de facultado) para evaluar los ofrecimientos y alegatos de las partes. En el modelo anterior, era conocido que las diligencias y au- 
diencias fueran delegadas por el juez a uno de sus subalternos. Para evitar esas prácticas, se estableció en la Constitución el principio de inmediación.

Resulta contradictorio que la legislación de Chihuahua establezca el principio de inmediación, pero solamente considere que la presencia del juez es requisito de validez en la audiencia intermedia y no así en las otras etapas.

Raúl Plascencia Villanueva señala que existe la inmediación formal y la material. La primera hace referencia a "la aspiración de que el juzgador se relacione lo más directamente con los medios de prueba, precisando de ser posible la práctica de los mismos". La segunda "obliga a los titulares de los tribunales a recibir por sí mismos las declaraciones y demás actos de prueba."

En el caso de Nuevo León, las únicas presencias que se requieren para que cobre validez una audiencia son las del Ministerio Público y el defensor del inculpado. La falta descrita en el párrafo anterior también es válida para este estado.

El artículo 20, fracción V, de la Constitución, señala que la carga de la prueba corresponde a la parte acusadora. Quien debe demostrar que el imputado cometió un delito es quien acusa. La legislación de Nuevo León no lo contempla. Más adelante en el texto se refuerza esta aseveración con lo tocante a la presunción de inocencia.

El mismo artículo brinda igualdad procesal para las partes. Los involucrados tienen igual derecho a ofrecer pruebas, ser escuchados, etcétera. En el modelo anterior, "las pruebas presentadas por el Ministerio Público en el expediente, siempre que se ajusten a los parámetros que establece la ley, tendrán valor probatorio pleno. Es decir, valdrán más que una prueba en contrario presentada por el acusado" (Carbonell y Reza, 2008).

A esto hay que sumar el principio de inmediatez, el cual implica que "las pruebas recabadas por el Ministerio Público con mayor proximidad a los hechos delictivos, tendrán mayor valor probatorio que las pruebas recabadas con posterioridad".

El Código de Procedimientos Penales de Nuevo León no señala explícitamente el principio de igualdad procesal. Se puede inferir que existe algo de eso cuando uno de sus principios es la contradicción, y se menciona que las partes debatirán en las audiencias.

La fracción sexta del artículo en comento también tiene que ver con la igualdad procesal en el sentido de que el juez no puede tratar un asunto con una sola de las partes presentes. Deben estar presentes ambas. Mientras que 
la legislación de Chihuahua sí contempla este aspecto, la de Nuevo León claramente no aboga por la igualdad procesal.

La fracción novena hace referencia a un requisito de validez para las pruebas. Si se quiere que las pruebas ofertadas sean aceptadas, no pueden ser obtenidas violando derechos fundamentales. La legislación de Chihuahua lo contempla. En la de Nuevo León se infiere que las pruebas obtenidas de manera ilegal pueden no ser válidas. Las partes pueden manifestarse en contra de una prueba por ser ilegal y el juez deberá pronunciarse al respecto.

El siguiente apartado a comentar es el de la presunción de inocencia. El nuevo sistema gira en torno a ésta. Por eso las medidas cautelares privativas de la libertad buscan ser la excepción y se asegura un catálogo amplio de derechos para el inculpado, entre otras cosas. "El imputado deberá ser considerado y tratado como inocente en todas las etapas del proceso, mientras no se declare su culpabilidad por sentencia firme", señala la legislación chihuahuense.

En el Código de Procedimientos Penales de Nuevo León se infiere lo contrario. Además de no enunciar dicho principio, el artículo 368 fracción séptima establece que el sobreseimiento procederá "cuando existan pruebas que acrediten fehacientemente la inocencia del acusado". Se debe probar que el acusado no es culpable.

En cuanto a la duración máxima de la prisión preventiva, Chihuahua cumple con el requisito de no exceder el tiempo máximo que fija el delito. De hecho, en lugar de señalar que no se podrá sobrepasar la pena máxima prevista, dice "mínima".

El Código de Procedimientos Penales de Nuevo León no incluye este precepto. El Código Penal castiga a los servidores públicos que prolonguen la prisión preventiva por más tiempo del que como máximo exija la ley. Los legisladores saben que existen plazos marcados por la Constitución, pero no lo incluyeron en su Código.

La Constitución considera la reparación del daño como derecho de la víctima, mientras que en Chihuahua se establece como principio del proceso. En Nuevo León, el enfoque es distinto. Se establece que el Ministerio Público puede exigir la reparación del daño, pero no se asegura que lo haga porque, a pesar de que la víctima puede solicitarla, no es uno de los ejes del proceso, como en Chihuahua.

Por último, es interesante mencionar que la legislación de Chihuahua prevé la figura de la indemnización cuando se afecten derechos durante el 
proceso. Este es un ejemplo de cómo se pueden ampliar los derechos en la legislación secundaria.

\section{El proceso penal en Nuevo León}

\section{Etapas del Procedimiento en Nuevo León (A)}

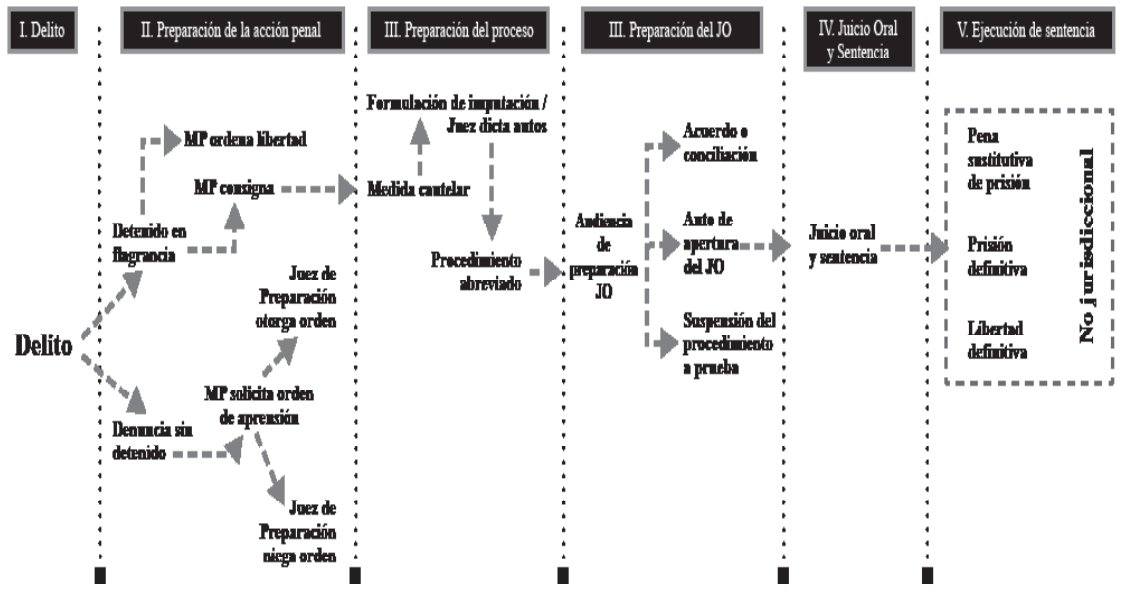

Fuente: Escuela de Graduados en Administración Pública y Política Pública.

En la legislación penal de Nuevo León confluyen dos sistemas distintos. El mixto y el acusatorio. Esto obedece a una doble gradualidad para la implementación de la reforma penal en el estado. El primer rubro de la gradualidad es el número de delitos que abarca el nuevo sistema.

Entre agosto del 2004 y junio de 2007, paulatinamente se agregaron delitos a la lista de los que deberían desahogarse por la vía oral. Se inició con los delitos culposos no graves (homicidio, lesiones y daño en propiedad ajena relacionados con accidentes viales cuando no se esté en estado de intoxicación voluntaria).

Después se extendió para los delitos culposos graves (quebrantamiento de sellos, estupro, abandono de cónyuge, incumplimiento injustificado de pago de pensión alimenticia, substracción de menores, apoderamiento ilegal de hijos, amenazas, golpes y violencias físicas sin lesión, entre otros), los perseguibles por querella y para delitos de oficio no graves con condena máxima de tres años de prisión. 
El otro rubro de la gradualidad es el de las etapas del procedimiento. Esto quiere decir que solamente se ha adoptado el nuevo sistema en ciertas etapas del procedimiento: preparación del juicio oral y juicio oral. La averiguación previa y la segunda instancia aún se llevan a cabo en el formato anterior.

La doble gradualidad representa un problema para el correcto funcionamiento del sistema, a pesar de que inicialmente parezca adecuado implementar los cambios paulatinamente. Los delitos que se persiguen en el nuevo sistema son mayoritariamente de baja incidencia (39 versus 16) (Arenas Bátiz).

Si lo que se busca es aprender de la experiencia, los delitos de baja incidencia difícilmente la proporcionarán. Más aún, han transcurrido más de tres años desde la incorporación de delitos de mayor incidencia, sin que haya habido más reformas para incorporar más delitos.

Sobre la gradualidad en las etapas, es importante mencionar que puesto que la etapa de preparación de la acción penal se sigue en el viejo modelo, no existe la figura del juez de control.

Además, "Genera operadores duales del sistema (jueces penales que atienden asuntos en materia de procedimiento oral y procedimiento tradicional), con la consecuente confusión en el manejo de los asuntos" (Ayala Chapa et. al).

Tampoco existe un plan definido para darle continuidad a la reforma, por lo que "se abre la posibilidad de que sus avances o retrocesos se den de manera azarosa, sin criterios ciertos, claros definidos y fundamentados, dejándola, simplemente, al vaivén de las circunstancias" (Ayala Chapa et. al, p. 46).

En las etapas de preparación del proceso y preparación de juicio oral, la legislación utiliza indistintamente los términos sujeción a proceso y auto de formal prisión. Dichos términos tienen consecuencias distintas. Mientras que uno es típico del sistema inquisitivo porque tiende a la prisión preventiva, el otro es solamente un aviso de que se iniciará un procedimiento penal en su contra.

En cuanto a la ejecución de la sentencia, en el gráfico A se puede apreciar que corresponde al ejecutivo. Si bien la Constitución no establece la figura del juez de ejecución de sentencia, ésta es recomendable puesto que de ese modo se separan las funciones administrativas de la ejecución de sentencias (Rivera Montes de Oca, 2003). 
El catálogo de penas no privativas de la libertad es corto. Consta de dos, a saber: multa y trabajo en beneficio de la comunidad. Las salidas alternas también son dos: suspensión del procedimiento a prueba y procedimiento abreviado.

La reparación del daño, por lo general también considerada como salida alterna, no lo es en este caso, puesto que resarcir el daño no es garantía de salir en libertad. Más bien se emplea como complemento. La cuarta y última salida alterna posible (no empleada en Nuevo León) es el criterio de oportunidad. Existe bibliografía (véase Ma. Victoria Berzosa) que pone en duda la utilización de esta salida. Si el delito en cuestión es de escasa lesión social, ¿tiene caso mantener la tipificación?

Sobre la legislación que regula el procedimiento aquí descrito, es importante mencionar que, quizá debido a una falta de técnica legislativa, resulta confusa. En primer lugar porque una parte del Código de Procedimientos Penales está dedicada al sistema mixto, mientras que otra al acusatorio adversarial, aunque ésta última toma las primeras etapas del primero. En segundo lugar, los capítulos, títulos y artículos no tienen nombre, lo que dificulta la búsqueda.

En tercer lugar, algunos elementos importantes no están explícitos en el texto, sino que se infieren por las circunstancias que se describen (ver tabla comparativa). Esto provoca una falta de certeza jurídica para todas las partes.

\section{El proceso penal en Chihuahua}

Etapas del Procedimiento en Chihuahua (B)

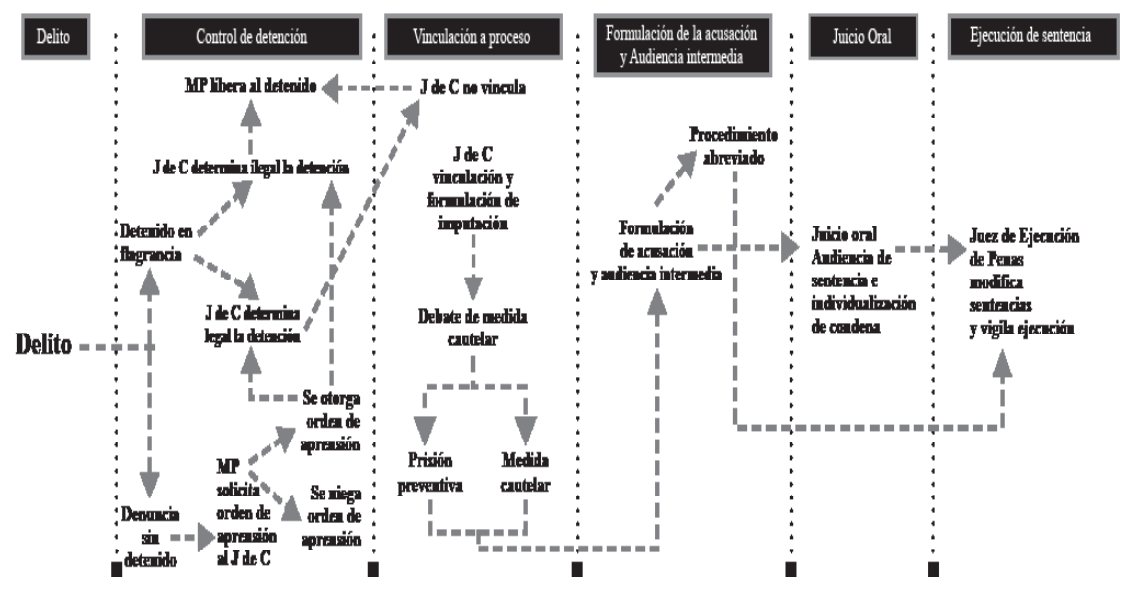


El sistema penal de Chihuahua experimentó un cambio total cuando abrogó su Código de Procedimientos Penales y expidió uno nuevo en junio de 2006. Su aplicación fue progresiva, por distritos y válido para todos los delitos.

El sistema de Chihuahua incluye la figura de juez de control, quien funge como contrapeso a las acciones del Ministerio Público en las primeras etapas del procedimiento. Asimismo, crea la figura del juez de ejecución de penas, el cual se encarga de modificar las sentencias impuestas cuando proceda, así como vigilar la correcta aplicación de las mismas.

El catálogo de penas no privativas de la libertad consta de cinco elementos: prohibición de residir o acudir a un lugar determinado, tratamiento en libertad (laboral, educativo, etcétera), sanciones pecuniarias, trabajo a favor de la comunidad y trabajo obligatorio con el fin de reparar el daño.

Si bien las opciones son amplias, siguen existiendo delitos inexcarcelables. Esto quiere decir que al cumplir con ciertos supuestos en un delito, la prisión preventiva es inevitable.

Establecer catálogos de delitos inexcarcelables es contrario a las directrices del Derecho Internacional de los derechos humanos a las que México, en ejercicio de su soberanía, ha aceptado ceñirse. En este caso, se violenta significativamente la lógica de un sistema acusatorio y protector de los derechos humanos (Zepeda Lecuona, 2010).

Lamentablemente no hay mucho que los legisladores locales podrían hacer puesto que es un mandato constitucional.

En cuanto a las salidas alternas que prevé son: acuerdos reparatorios, suspensión del proceso a prueba, criterio de oportunidad y procedimiento abreviado. Guillermo Zepeda Lecuona afirma que "Para que un sistema pueda instrumentar eficaz y eficientemente este modelo procesal, se requiere que no más del 7\% o 10\% de los casos llegue a juicio oral.” Por esta razón resulta importante incluir en la legislación las cuatro salidas alternas posibles.

\section{CONCLUSIONES Y RECOMENDACIONES}

De los dos estados analizados, Chihuahua es el que ofrece un mayor balance de derechos para las partes. Si las leyes penales "marcan el límite último de todo sistema de valores" (Soler, 1966), entonces puede aseverarse que Chihuahua refleja un espíritu pro derecho. Habrá que evaluar el uso que se hace del espacio que ofrece el marco que crearon. 
En la teoría, el modelo del estado en comento garantiza que los involucrados serán molestados lo menos posible. La excepción es la existencia de delitos inexcarcelables. Puesto que esto proviene de un mandato constitucional, el margen de maniobra sólo consta en reducir la lista a los mínimos que plantea la Constitución.

El otro aspecto a tomar en cuenta es la falta del principio de inmediación durante el juicio oral. En esta etapa es donde se valoran las pruebas y se dicta sentencia, por lo que abrir la posibilidad para dejarlo en manos de secretarios o actuarios sería dar un paso en la dirección equivocada.

En el caso de Nuevo León, mientras se continúen utilizando indistintamente los términos sujeción a proceso y auto de formal prisión, la presunción de inocencia no será un principio rector del sistema.

El modelo de Nuevo León parece ser más oral que acusatorio-adversarial. Dan indicios de ello los siguientes hechos: la reparación del daño no es un eje, la averiguación previa y la segunda instancia son parte del modelo anterior, el principio de inmediación es inexistente a pesar de que se enuncia y no se asegura la igualdad procesal de las partes.

El sistema acusatorio-adversarial es un intento por limitar los espacios para la corrupción y la impunidad. Depende de los actores hacer buen uso de las herramientas y no tergiversar el sentido del modelo. Los estados tendrán que tomar esto en cuenta y empezar a construir de acuerdo a su realidad.

La aspiración es que los comentarios para los modelos de los estados puedan ser utilizados como guía para no cometer los mismos errores.

\section{BIBLIOGRAFÍA}

Plascencia Villanueva, Raúl, "Los medios de prueba en materia penal", Semanario Judicial de la Federación, Octava Época, tesis J/48, febrero de 1995, t. XV.

OchoA ReZA, Enrique y CARBOnEll, Miguel, "Elementos para discutir el modelo de proceso penal que México necesita", Actualidad Judicial, Revista del Poder Judicial del Estado de Zacatecas, año 0, núm. 3, julio de 2008.

BÁtiz Arenas, Emilio, Procedimiento oral penal en Nuevo León. Principales rasgos, causas, efectos y defectos, Insyde.

AyAla CHAPA, Ma. de Lourdes et. al., La reforma al sistema de justicia penal en Nuevo León: sus principales tendencias (2004-2007), Nuevo 
León Renace Monterrey, diciembre de 2008.

RIVERA MONTES DE OCA, Luis, Juez de ejecución de penas. La reforma penitenciaria mexicana del Siglo XXI, México, Porrúa, 2003.

Berzosa Francos, Ma. Victoria, "Principios de legalidad y oportunidad en el proceso penal", Problemas actuales de la justicia penal, Barcelona, JM Bosch Editor, 2001.

ZEPEDA LECUONA, Guillermo, La reforma constitucional en materia penal de junio de 2008, ICESI.

SOLER, Sebastián, Bases ideológicas de la reforma penal. Colección Ensayos, Buenos Aires, Editorial Universitaria de Buenos Aires, 1966.

\section{Legislación}

Constitución Política de los Estados Unidos Mexicanos.

Código Penal del Estado de Chihuahua.

Código de Procedimientos Penales del Estado de Chihuahua.

Código Penal para el Estado de Nuevo León.

Código de Procedimientos Penales del Estado de Nuevo León.

Fecha de recepción: 14 de marzo de 2011.

Fecha de dictamen: 25 de abril de 2011. 